\title{
Geociências
}

\section{Aplicação da geologia de engenharia na redução de risco geológico urbano em Itapecerica da Serra - SP: estudo de caso} (Application of the geology of engineering in the reduction of
urban geologic risk in Itapecerica da Serra - SP: study of case)

\author{
Leonardo Andrade de Souza \\ Engenheiro Geólogo - Doutorando do PPECRN/DEGEO/UFOP.E-mail: geolsouza@yahoo.com.br \\ Fernando Rocha Nogueira \\ Geólogo,Dr., Autônomo.E-mail: fernandorn@uol.com.br \\ Leandro Eugenio da Silva Cerri \\ Geólogo, Prof. Adjunto - IGCE/Unesp-Rio Claro (SP).E-mail: lescerri@rc.unesp.br
}

\section{Resumo}

O município de Itapecerica da Serra, Região Metropolitana de São Paulo (RMSP), possui uma população de 162 mil habitantes e cerca de 150 km² de área. As características geológicas e geomorfológicas do seu território e o fato de localizar-se quase inteiramente em área de proteção aos mananciais que abastecem a RMSP implicam restrições ao uso do solo e à expansão da ocupação nos moldes em que vem ocorrendo. O diagnóstico das áreas de risco geológico do município foi uma das atividades implementadas para a execução do Plano Municipal de Redução de Riscos (PMRR) do município. O PMRR tem por objetivo apresentar os resultados da identificação e da análise das situações de risco geológico-geotécnico, criando propostas de intervenções estruturais para a sua eliminação e/ou redução, estimativas de custo e estratégias para a gestão de risco no município. O mapeamento do risco geológico foi realizado em 35 áreas, onde foram identificados 66 setores de risco englobando, 419 moradias, sendo 175 moradias em setores cujo grau de risco foi classificado como alto ou muito alto. As propostas de intervenção estrutural buscaram a aderência entre o processo geodinâmico atuante e a tipologia de intervenção sugerida para estabilização e controle. A definição de critérios para a hierarquização das intervenções propostas contribuiu para a inserção das propostas do PMRR no planejamento plurianual do município de Itapecerica da Serra.

Palavras-chave: Cartografia de risco, planejamento urbano, Plano Municipal de Redução de Riscos, Itapecerica da Serra, São Paulo.

\begin{abstract}
The municipality of Itapecerica da Serra is part of the metropolitan area of São Paulo, Brazil. It has about 162.000 inhabitants and a territorial extension of $150 \mathrm{~km}^{2}$. Most of its territory is included in an environmentally protected area. The diagnosis of areas with geological risk was implemented in order to increment the elaboration of a Local Risk Reduction Plan (PMRR). Besides the identification and analysis of geological and geo-morphological risk situations, the PMRR includes propositions for structural intervention aiming to eliminate or reduce risks, as well as cost estimates and general strategies for risk management. The diagnosis was implemented in 35 areas, in which 66 risk sectors were identified. These sectors involved 419 residences and, among them, 175 are located in sectors with high or very high risk. The proposals for structural intervention required coherence between active geodynamical processes and the kind of intervention proposed for stabilization and control. The definition of priority criteria for the proposed interventions contributed for the insertion of PMRR proposals into the pluri-annual plan of action established by the local government.
\end{abstract}

Keywords: Cartography of risk, urban planning, local risk reduction plan, Itapecerica da Serra, São Paulo. 
Aplicação da geologia de engenharia na redução de risco geológico urbano em Itapecerica da Serra...

\section{Introdução e objetivos}

O mapeamento das áreas de risco geológico do município de Itapecerica da Serra, São Paulo, foi objeto do contrato firmado entre a Prefeitura de Itapecerica da Serra (PMIS) e a Fundação de Apoio à Pesquisa, Ensino e Extensão (FUNEP), atendendo ao convênio firmado com a Caixa Econômica Federal/Ministério das Cidades, por meio do Programa de Urbanização, Regularização e Integração de Assentamentos Precários/ Ação de Apoio à Prevenção e Erradicação de Riscos em Assentamentos Precários.

O Plano Municipal de Redução de Riscos (PMRR) de Itapecerica da Serra (SP) foi executado por meio de estudos realizados no período de janeiro a maio de 2006 e teve como premissa fundamental a análise detalhada do ambiente urbano, principalmente no que tange à compreensão de como se dá a gestão desse ambiente, a partir das políticas públicas voltadas para as áreas de assentamento precário, a porção informal, vulnerável e, freqüentemente, degradada da cidade.

O PMRR propõe alguns referenciais técnicos e gerenciais que permitem aos Poderes Públicos a implementação de ações estruturais e não-estruturais, em prazos adequados aos recursos orçamentários do município, do Estado e da União, para reduzir e controlar as situações de riscos associadas a escorregamentos e solapamentos de margens de córregos que ameaçam a segurança dos moradores e dificultam a inclusão dos assentamentos precários à cidade formal.

A partir dos preceitos do Ministério das Cidades, os estudos aqui apresentados contemplaram: 1) a realização de identificação e análise de risco geológico nas áreas de ocupação irregular do município, com delimitação de setores de risco e quantificação das moradias expostas à situação identificada de risco; 2) a definição das intervenções necessárias para erradicação de risco em cada setor mapeado, contendo a tipolo- gia e quantitativos das obras sugeridas e indicação de remoções e serviços quando necessários; 3) a estimativa de custos para cada intervenção; 4) a hierarquização das intervenções propostas. Esse trabalho teve como foco as tipologias de risco geológico relacionadas a escorregamentos e solapamento de margens de córrego. Esses processos, em áreas urbanas, podem movimentar, além de rochas, solo e vegetação, depósitos artificiais (lixo, aterros, entulhos) ou materiais mistos, caracterizando processos geológicos, geomórficos ou geotécnicos.

Diferentemente dos zoneamentos de áreas de risco, esse trabalho de cadastramento foi executado com um grau de detalhe maior, sendo que os riscos são identificados e analisados na escala referente a um lote, moradia por moradia, somando-se a isto proposições voltadas ao estabelecimento de referenciais e diretrizes para o desenvolvimento e implantação de ações para que o plano se tornasse público e apropriado pela população envolvida, desenvolvendo-se, para tal, um trabalho educativo, informativo e de mobilização junto à população moradora de áreas de risco, através das lideranças comunitárias e de entidades da sociedade civil.

\section{Material e métodos}

Adotou-se, como referenciais para esse trabalho, a metodologia indicada pelo Ministério das Cidades (Brasil, 2006) e a proposta de Santos (2002), que estabelece um roteiro de trabalho (Quadro 1) para as atividades do profissional das áreas de geologia de engenharia e geotecnia frente a um determinado problema.

O tipo de mapeamento adotado para as áreas de risco foi o heurístico, a partir do mapeamento direto, baseado em levantamentos de campo e mapa de detalhe, sendo risco geológico definido por Cerri (1990) como uma situação de perigo, perda ou dano, ao homem e a suas propriedades, em razão da possibilidade de ocorrência de processos geológicos, induzidos ou não.
A equação mais simples e didática utilizada para representar risco é:

$\mathrm{R}=\mathrm{P} \times \mathrm{C}$

Sendo: $\mathrm{R}=$ risco; $\mathrm{P}=$ probabilidade (ou possibilidade) de ocorrência de um determinado evento adverso (evento perigoso); $\mathrm{C}=$ conseqüências sociais e/ou econômicas potencias.

\subsection{Circunscrição do problema}

A circunscrição da análise do risco geológico ocorreu, inicialmente, através de uma pré-setorização do município de Itapecerica da Serra subsidiada pela percepção dos profissionais envolvidos e por parâmetros básicos utilizados comumente na caracterização do meio físico, tais como declividade/inclinação, tipologia dos processos, posição da ocupação em relação à encosta e qualidade da ocupação (vulnerabilidade). Essa análise preliminar abrangeu todas as áreas de favelas e loteamentos precários do município de Itapecerica da Serra, onde, na cultura técnica dos agentes públicos, houvesse moradias sujeitas a acidentes ou, ainda, registro de ocorrência de acidentes associado a escorregamentos de encostas, solapamento de margens de córregos ou ação direta das águas pluviais (enxurradas). O resultado dessa análise foi a seleção de 35 áreas para o mapeamento do risco geológico.

As 35 áreas definidas foram visitadas, preliminarmente, para uma avaliação expedita de suas características e a obtenção de coordenadas geográficas por meio de GPS (Global Position System). Tais ações visavam a delimitar as referidas áreas, aproximadamente, e a orientar, posteriormente, o plano de vôo para tomada de fotos oblíquas de baixa altitude. Em 33 áreas, das 35 selecionadas, foram obtidas fotos oblíquas, por meio de vôo de helicóptero a alturas médias entre 100 a 150 metros do solo. As cópias em papel das fotos obtidas nesse vôo foram utilizadas em campo para a delimitação dos setores de risco identificados durante os trabalhos de campo. 
Leonardo Andrade de Souza et al.

Quadro 1 - Roteiro e seqüência de atividades na Geologia de Engenharia (Santos, 2002).

\begin{tabular}{c|l|l}
\hline $\begin{array}{c}\text { Fases do } \\
\text { Trabalho }\end{array}$ & \multicolumn{1}{|c}{ Objetivo } & \multicolumn{1}{c}{ Principais Cuidados } \\
\hline $\begin{array}{c}\text { Circunscrição } \\
\text { do } \\
\text { problema }\end{array}$ & $\begin{array}{l}\text { Identificação preliminar dos problemas } \\
\text { potenciais ou ocorridos. } \\
\text { Enquadramento geológico-geomorfológico do } \\
\text { local. } \\
\text { Delimitação e caracterização da área de } \\
\text { trabalho. }\end{array}$ & $\begin{array}{l}\text { Recolhimento de todos os registros } \\
\text { bibliográficos e técnicos e de testemunhos de } \\
\text { pessoal local. } \\
\text { Caracterização das feições e dos processos } \\
\text { geológico-geomorfológicos naturais locais e } \\
\text { regionais presentes. }\end{array}$ \\
$\begin{array}{c}\text { Análise e } \\
\text { diagnóstico dos } \\
\text { fenômenos } \\
\text { presentes }\end{array}$ & $\begin{array}{l}\text { Caracterização dos parâmetros geológicos e e } \\
\text { geotécnicos necessários ao entendimento } \\
\text { dos fenômenos envolvidos. } \\
\text { Diagnóstico final e descrição qualitativa e } \\
\text { quantitativa dos fenômenos implicados nas } \\
\text { inter-relações solicitações / meio físico. }\end{array}$ & $\begin{array}{l}\text { Pesquisa de situações semelhantes, } \\
\text { especialmente na região. } \\
\text { Identificação dos processos geológicos e } \\
\text { geotécnicos originalmente presentes. } \\
\text { Adoção de hipóteses fenomenológicas } \\
\text { progressivas e esforço investigativo e } \\
\text { observativo para sua aferição. }\end{array}$ \\
\hline $\begin{array}{c}\text { Formulação } \\
\text { de }\end{array}$ & $\begin{array}{l}\text { Apoio à engenharia na formulação das } \\
\text { soluções adequadas. }\end{array}$ & $\begin{array}{l}\text { Zelo especial pela perfeita aderência solução / } \\
\text { fenômeno. } \\
\text { Busca do barateamento da solução } \\
\text { encontrada. }\end{array}$ \\
\hline
\end{tabular}

\subsection{Análise e diagnóstico do risco geológico}

Definidas as áreas e suas características principais, deu-se início aos trabalhos de campo, através do mapeamento de detalhe e setorização do risco. Os setores de risco indicam um espaço definido dentro do assentamento sujeito a sofrer um determinado processo destrutivo, cujas evidências ou indicadores predisponentes foram identificados em campo.

Os seguintes procedimentos/etapas foram definidos:

1. Vistorias de campo em cada uma das áreas estudadas, por meio da realização de investigações geológico-geotécnicas de superfície, visando a identificar os setores de risco através dos condicionantes dos processos de instabilização, evidências de instabilidade e indícios do desenvolvimento de processos destrutivos (Quadro 2).

2. Registro em fichas de campo padrão das características de cada área es- tudada e dos setores delimitados no interior das mesmas, com os resultados das investigações geológico-geotécnicas realizadas na etapa 1.

3. Delimitação dos setores de risco, representando-os nas cópias das fotografias de helicóptero (Figura 1 exemplo). Para a complementação dos registros de indicativos de risco observados em campo, além das fotos de helicóptero, foram obtidas fotografias “de chão” de detalhe, durante os trabalhos de campo.

4. Atribuição, para cada setor de risco, do grau de probabilidade de ocorrência de processo de instabilização (escorregamento de encostas e solapamento de margens de córregos), considerando o período de um ano e com base nos critérios propostos pelo Ministério das Cidades.

\section{R1 - Risco Baixo a Inexistente. \\ R2 - Risco Médio. \\ R3 - Risco Alto.}

R4 - Risco Muito Alto.

\subsection{Formulação de soluções e hierarquização das intervenções}

Na etapa de formulação e hierarquização das intervenções, ocorreu a estimativa das conseqüências potenciais do processo de instabilização, por meio da avaliação das possíveis formas de desenvolvimento do processo destrutivo atuante (por ex., volumes mobilizados, trajetórias dos detritos, áreas de alcance, etc.) e do número de moradias ameaçadas, em cada setor de risco.

Posteriormente, e embasado no pressuposto anteriormente apresentado, o próximo passo foi a indicação $\mathrm{da}(\mathrm{s})$ alternativa(s) de intervenção adequada(s) para cada setor de risco, destacando-se: serviços de limpeza e recuperação, obras de drenagem e proteção superficial, retaludamentos, desmonte de blocos e matacões, obras de drenagem de subsuperfície, estruturas de contenção de pequeno porte cujas alturas não ultrapassam 3,0 m, estruturas de contenção de médio 
Aplicação da geologia de engenharia na redução de risco geológico urbano em Itapecerica da Serra...

Quadro 2 - Check-list dos condicionantes dos processos de instabilização, evidências de instabilidade e indícios do desenvolvimento de processos destrutivos observados no campo.

\begin{tabular}{|c|c|}
\hline CARACTERIZAÇÃO DO LOCAL & EVIDÊNCIAS/INDÍCIOS DE MOVIMENTAÇÃO \\
\hline Talude natural / corte & Trincas moradia/aterro \\
\hline Altura do talude & Inclinação de árvores / postes / muros \\
\hline Aterro compactado/lançado & Degraus de abatimento \\
\hline Distância da moradia & Cicatrizes de escorregamentos \\
\hline Declividade & Feições erosivas \\
\hline Estruturas em solo / rocha desfavoráveis & Muros / paredes "embarrigados" \\
\hline $\begin{array}{l}\text { Presença de blocos de rocha/matacões / } \\
\text { paredões rochosos }\end{array}$ & $\begin{array}{c}\text { ÁGUA } \\
\text { Concentração de água de chuva em superfície }\end{array}$ \\
\hline Presença de lixo/entulho & Lançamento de água servida em superfície \\
\hline Aterro em anfiteatro & Presença de fossas / rede de esgoto / rede de água \\
\hline Ocupação de cabeceira de drenagem & $\begin{array}{l}\text { Nascentes d'água } \\
\text { Vazamentos }\end{array}$ \\
\hline VEGETAÇÃO NO TALUDE OU PROXIMIDADES & MARGENS DE CÓRREGO \\
\hline Presença de árvores & Tipo de canal (natural / sinuoso / retificado) \\
\hline Vegetação rasteira & Distância da margem \\
\hline Área desmatada & Altura do talude marginal \\
\hline Área de cultivo & $\begin{array}{l}\text { Altura de cheias } \\
\text { Trincas na superfície do terreno }\end{array}$ \\
\hline
\end{tabular}

a grande porte cujas alturas são superiores a 3,0 m, obras lineares de proteção de margens de canais e remoção de moradias.

Após a indicação e quantificação das intervenções, bem como a estimativa de custos para cada setor de risco, procedeu-se a elaboração de uma proposta para hierarquização das obras de redução de risco, considerando a prioridade das mesmas na gestão urbana como um todo.

\section{Aspectos da geologia e geomorfologia da área}

Itapecerica da Serra localiza-se a sudoeste da bacia Sedimentar de São

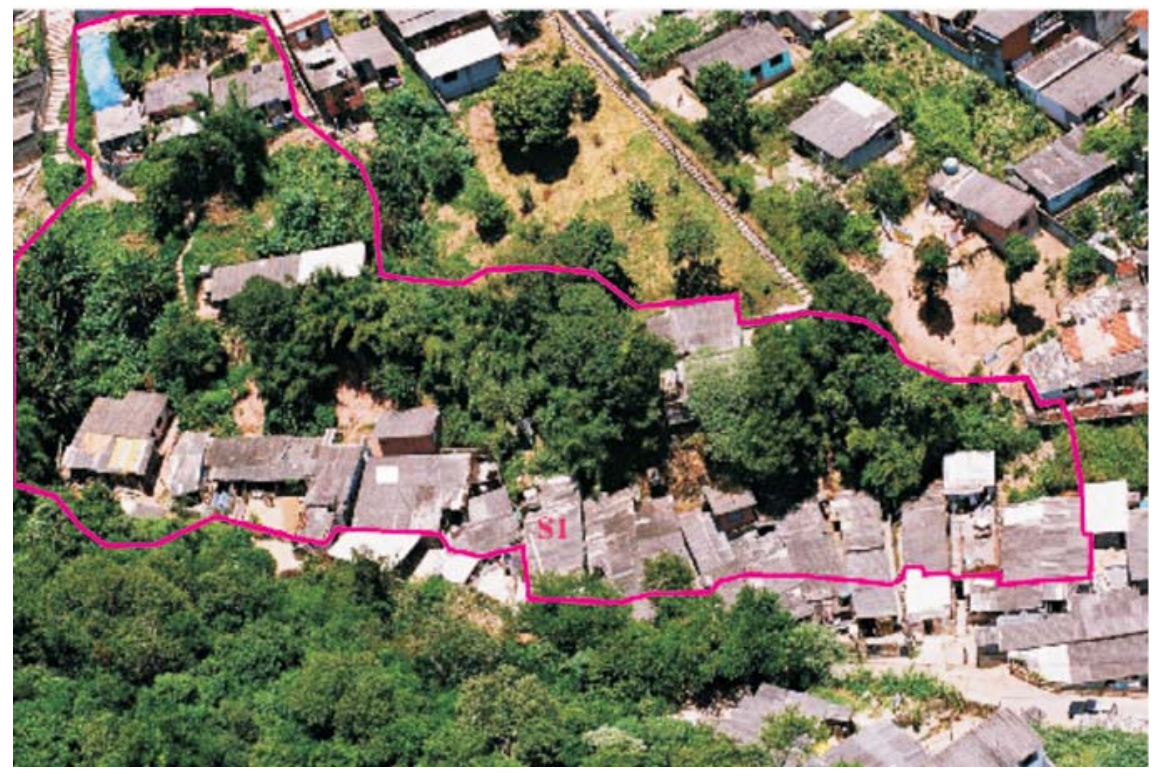

Figura 1 - Delimitação do setor de risco mapeado a partir da foto oblíqua (ex - Jardim Paraíso, Setor 1). 
Leonardo Andrade de Souza et al.

Paulo. A geologia do município é caracterizada pela presença predominante de rochas cristalinas do embasamento PréCambriano (migmatitos, gnaisses graníticos e gnaisses miloníticos). Também ocorrem porções expressivas de mica xistos e metarenitos de médio grau metamórfico, incluindo xistos miloníticos e sedimentos quaternários depositados nas várzeas dos rios atuais. A ocorrência de sedimentos terciários associados à bacia Sedimentar de São Paulo é restrita, limitando-se à porção leste do município (Figura 2).

A geomorfologia do município caracteriza-se pela presença de relevos suavizados, até porções com amplitude e declividade mais acentuadas, com altitudes entre 800 e 900 metros.

Nesse estudo, para o enquadramento geomorfológico, foram adotadas as seguintes definições, que subsidiaram as descrições que compõem as fichas de campo das áreas e setores de risco geológico:

- Planícies aluviais: quatro áreas com ocorrência de processos geodinâmi- cos onde predominam baixas declividades, inferiores a 5\% e nível freático pouco profundo.

- Morrotes: duas áreas com ocorrência de processos geodinâmicos onde predominam amplitudes de 50m e declividades de $20 \%$ mas com ocorrências restritas de áreas com declividades maiores que $30 \%$.

- Morros baixos: 21 áreas com ocorrência de processos geodinâmicos, onde predominam amplitudes de $100 \mathrm{~m}$ e declividades de até 30\%.

- Morros altos: sete áreas com ocorrência de processos geodinâmicos, onde predominam amplitudes de 150 m e declividades elevadas, maiores que $30 \%$.

- Áreas planas: uma área com ocorrência de processos geodinâmicos (topo de morro).

\section{4. Áreas de risco geológico-geotécnico}

Em decorrência da escala de detalhe adotada no mapeamento dos setores de risco identificados, estes foram delimitados a partir das fotos oblíquas de helicóptero e de “chão”. Entretanto, para uma contextualização em nível municipal, na Figura 3 está indicada, pontualmente, a localização das áreas mapeadas no município de Itapecerica da Serra, onde foram identificados setores com predisposição ao risco geológico, classificados com alto e muito alto.

\section{Resultados}

Nas 35 áreas selecionadas, para o mapeamento, foram delimitados 66 setores de risco geológico-geotécnico, sendo 61 setores localizados em encostas e 5 setores em margem de córregos.

Nos 66 setores delimitados, um setor foi descrito com grau de probabilidade à deflagração de processos geodinâmicos "muito alto”, 20 setores com grau de probabilidade “alto”, 39 setores com grau de probabilidade "médio” e, finalmente, 6 setores com probabilidade "baixa” a “inexistente” (Figura 4).

Em termos dos processos geodinâmicos identificados, 52\% das situações

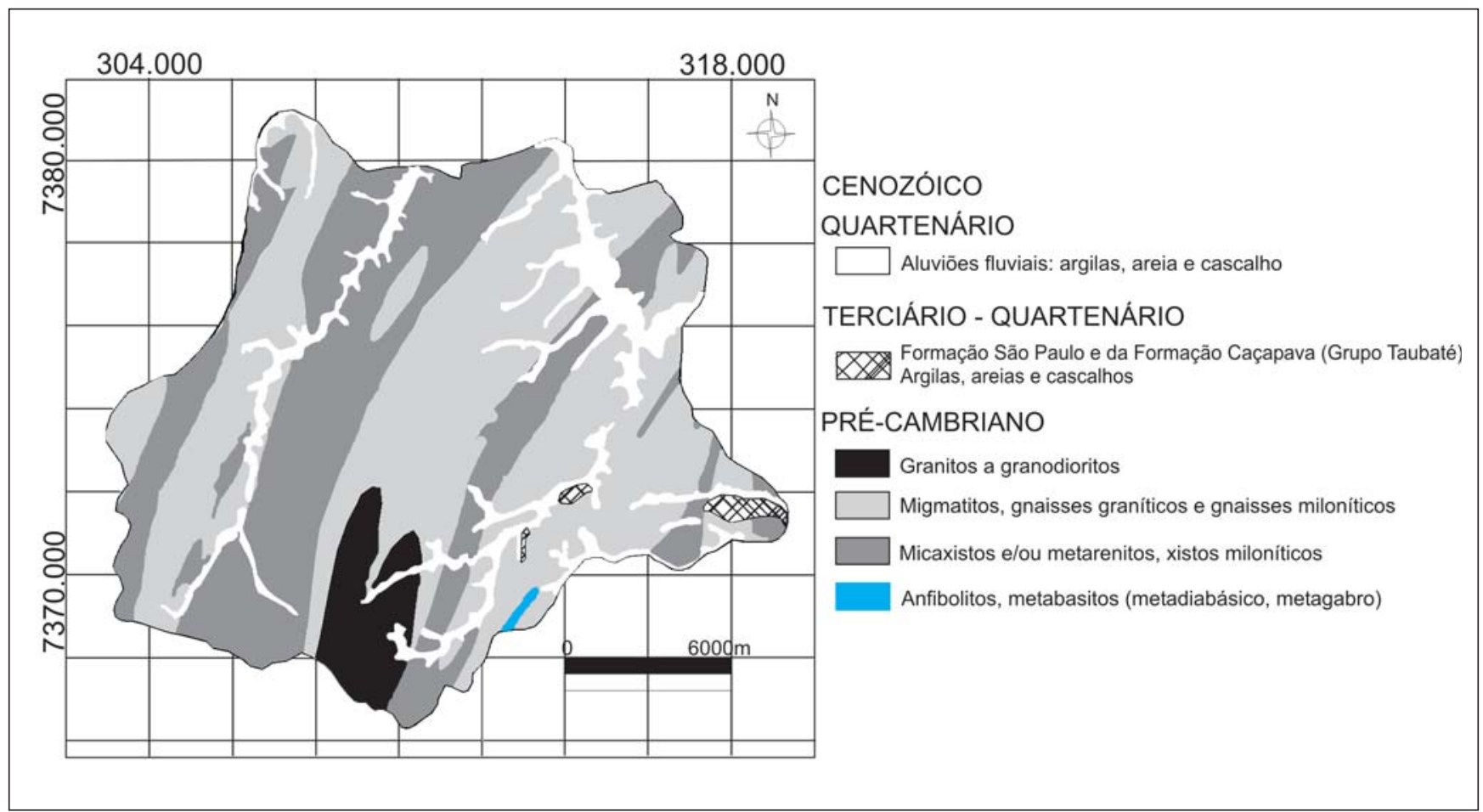

Figura 2 - Mapa geológico do município Itapecerica da Serra. Fonte: Empresa Metropolitana de Planejamento da Grande São Paulo. Carta geológica da região metropolitana da Grande São Paulo. Escala 1:100.000. 1980. 


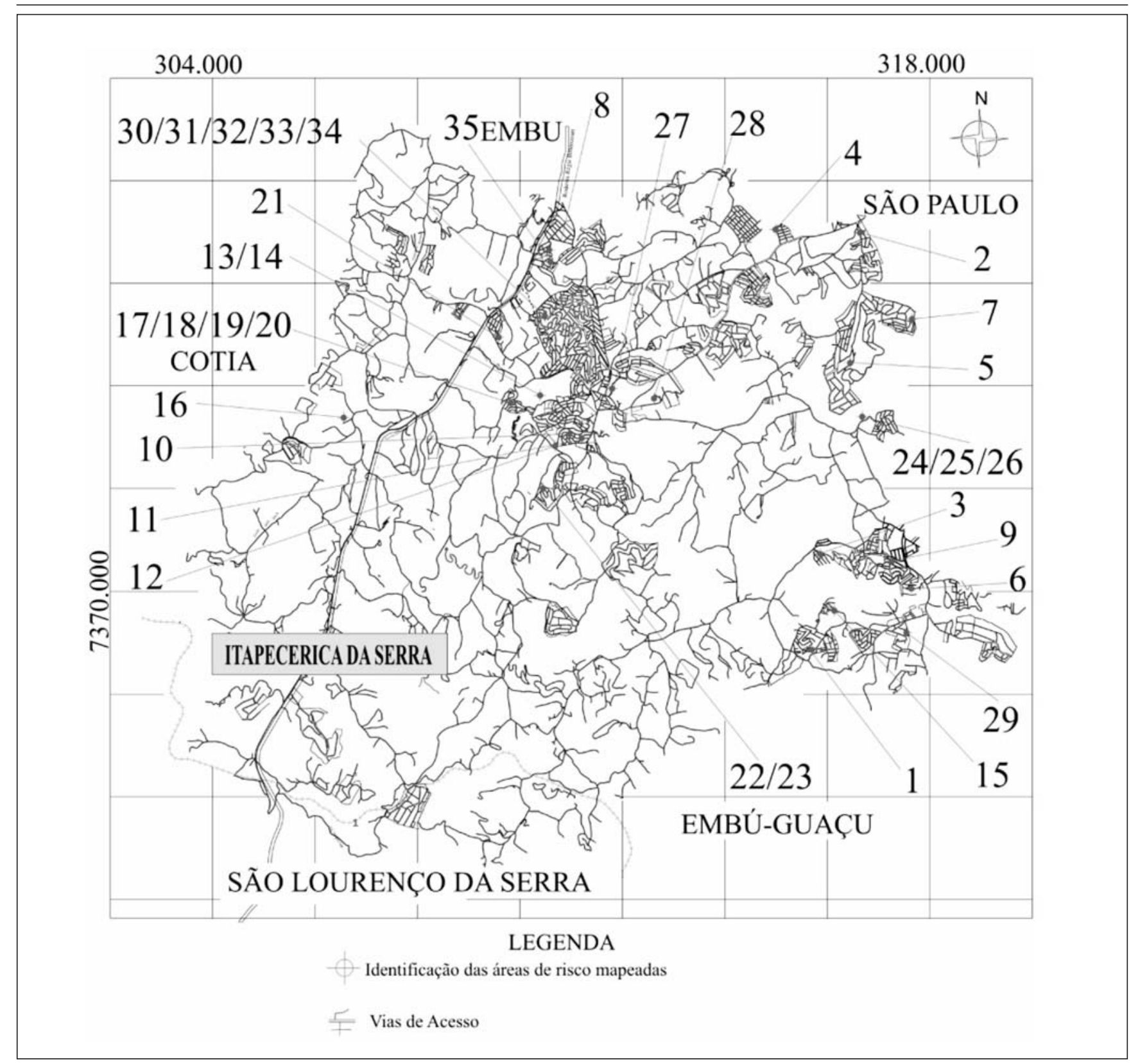

Figura 3 - Localização das áreas do município de Itapecerica da Serra onde foram mapeadas situações de risco geológico.

de risco estão associadas a escorregamentos translacionais rasos e rotacionais de solo, $32 \%$ a processos erosivos, $9 \%$ a ação direta das águas superficiais (enxurradas), $4 \%$ a solapamentos em margens de córregos e $3 \%$ a enchentes/inundação (Figura 5).

Nos 66 setores de risco delimitados, foram identificadas 419 moradias que se encontram ameaçadas, das quais quatro foram classificadas com grau de probabilidade "muito alto", sendo estas indicadas para remoção imediata; 175 classificadas com grau de probabilidade "alto"; 209 com grau de probabilidade "médio" e 31 com grau de probabilidade "baixo".

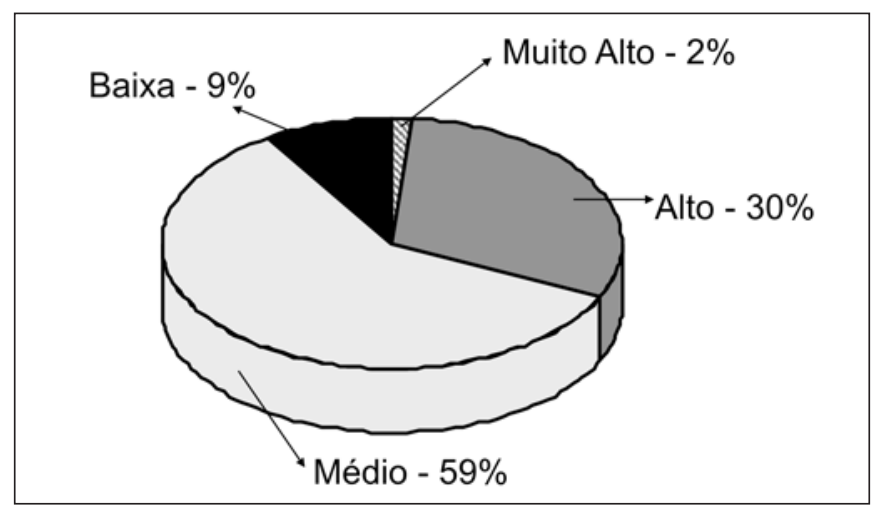

Figura 4 - Percentual do número de setores e os diferentes graus de probabilidade de ocorrência de processos perigosos. 
Os casos mais críticos observados em campo receberam, por parte da equipe técnica, atenção imediata com orientação aos próprios moradores ou responsáveis e indicação de medidas para a Prefeitura Municipal, conforme registrado nas fichas de campo.

\section{Critérios para priorização das intervenções}

Visando ao estabelecimento de uma ordem de prioridade entre as áreas e setores a serem atendidos por intervenções estruturais de redução de risco, foram adotados os critérios descritos a seguir.

1. O grau de risco (probabilidade de ocorrência de processos destrutivos).

Prioridade para os setores de risco muito alto (R4), alto (R3), médio (R2) e, finalmente, baixo (R1).

2. O porte do setor (prioridade para os casos que resultem em maior número de moradias beneficiadas diretamente com a intervenção proposta), sendo:

- Setor de grande porte (>20 moradias em risco).

- Setor de médio porte (entre 10 e 20 moradias).

- Setor de pequeno porte (menos que 10 moradias em risco).

3. A relação custo/moradia da intervenção estrutural: prioridade para as situações que apresentam menor relação custo/moradia.

4. A inclusão da área ou setor em programas municipais de urbanização, regularização fundiária ou saneamento.

- Prioridade 1: setor com risco geológico muito alto (R4).

- Prioridade 2: setores com intervenções com custo por moradia atendida baixo (<R $\$ 1.000,00)$.

- Prioridade 3: áreas com processo de regularização fundiária em andamento (embora nem todos os setores de risco das áreas 17 a 20 sejam de grau de

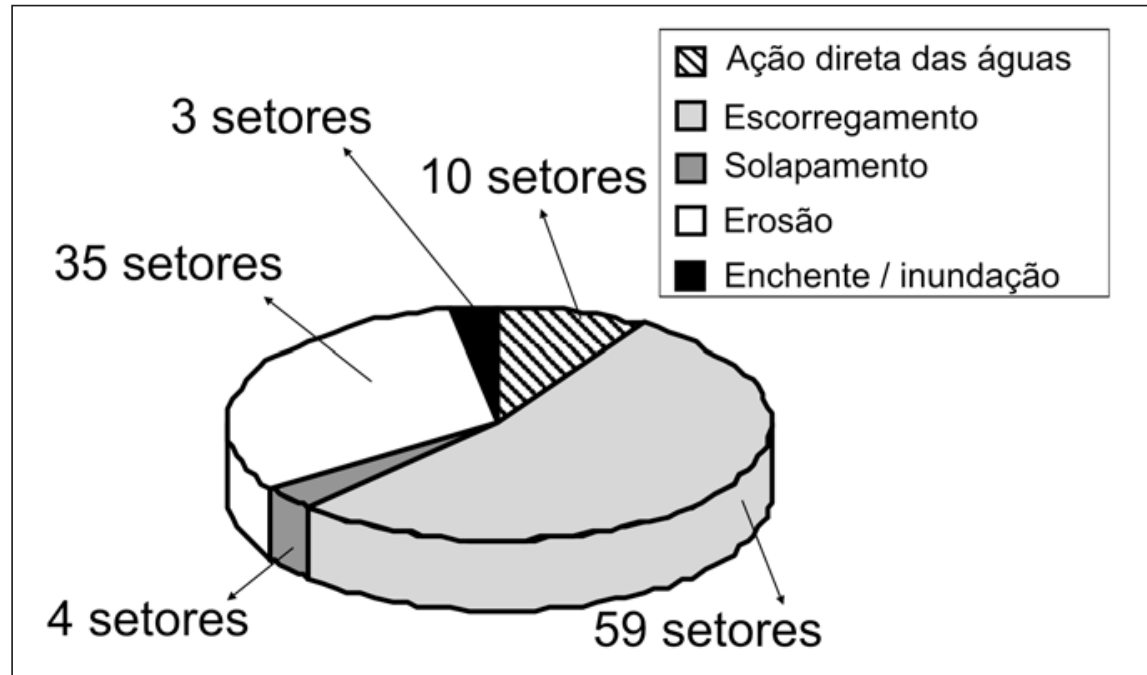

Figura 5 - Relação entre o número de setores mapeados e tipologia dos diferentes processos geodinâmicos, referentes às situações de risco identificadas.

probabilidade “alto”, estas áreas foram priorizadas em razão de projetos de regularização da Prefeitura Municipal de Itapecerica da Serra).

- Prioridade 4: setores de médio a grande portes com intervenções com custo por moradia atendida médio (entre $\mathrm{R} \$ 1.000,00$ e $\mathrm{R} \$ 5.000,00)$.

- Prioridade 5: setores de menor porte com intervenções com custo por moradia atendida (entre $\mathrm{R} \$ 1.000,00 \mathrm{e}$ $\mathrm{R} \$ 5.000,00)$.

- Prioridade 6: setores com intervenções com custo por moradia atendida alto (> R\$5.000,00).

O Quadro 3 apresenta o resultado da aplicação dos critérios de hierarquização descritos, com as classes de prioridades entre os setores de riscos alto e muito alto (R3 e R4) mapeados, sendo que esse resultado deverá a partir do presente estudo servir como referência para as ações de redução de riscos em Itapecerica da Serra.

\section{Conclusões}

O Plano de Intervenções Estruturais para o município de Itapecerica da Serra, que corresponde a uma das etapas do Plano Municipal de Redução de Risco - PMRR, que além das ações estruturais também prevê ações não estru- turais, demonstrou ser possível, a partir de estudos dessa natureza, viabilizar a melhoria das condições de convivência com o risco nesse município e em outros, a curto e médio prazo.

Especificamente, para Itapecerica da Serra, apontou a necessidade de intervenções imediatas para eliminação das situações de risco alto e muito alto.

Foram identificados, no município de Itapecerica da Serra, um setor de risco com grau de probabilidade MUITO ALTO, contendo quatro moradias ameaçadas, e vinte setores de risco com grau de probabilidade ALTO, contendo 175 moradias ameaçadas.

Para as moradias em risco das áreas Jardim do Carmo, Jardim Itapecerica, Parque Santa Amélia e Vila Geni, devem ser realizados monitoramentos permanentes das situações de risco, até a completa remoção prevista em projetos da Prefeitura e, eventualmente, implantadas intervenções emergenciais, caso ocorra evolução das situações de risco descritas.

As intervenções estruturais sugeridas estão subordinadas, quase que exclusivamente, à avaliação das condições de risco (ao processo perigoso identificado, ao seu estágio de desenvolvimento e à tipologia de obra adequada à eliminação ou redução da possibilidade de ocorrência do processo perigoso, ou pro- 
Aplicação da geologia de engenharia na redução de risco geológico urbano em Itapecerica da Serra...

cesso destrutivo). À municipalidade de Itapecerica da Serra caberá optar por solução diversa daquela indicada se, porventura, às alternativas de intervenção para redução de risco se sobrepuserem projetos de interesse coletivo, de proteção ambiental ou de desenvolvimento urbano que requisitem a remoção de assentamentos ou de moradias.

Sugere-se que o mapeamento de risco aqui apresentado seja utilizado para ações preventivas e monitoramento de campo durante os períodos críticos de pluviosidade, principalmente, a implantação de Planos Preventivos de Defesa Civil nos períodos chuvosos, indispensável para a garantia da segurança dos moradores das áreas mais críticas, até que se execute a intervenção estrutural planejada.

\section{Referências bibliográficas}

BRASIL, MINISTÉRIO DAS CIDADES.

Treinamentos de técnicos municipais para o mapeamento e gerenciamento de áreas urbanas com risco de escorregamentos, de enchente e de áreas contaminadas. Programa de Prevenção e Erradicação de Riscos, Secretaria de Programas Urbanos, disponível no site http:/ www.cidades.gov.br, acessado em junho de 2006.

CERRI, L.E.S., AUGUSTO FILHO, O. Riscos geológicos associados à ocupação de encostas no Brasil: um roteiro metodológico para a ação da Defesa Civil e de urbanistas. In: SIMPÓSIO LATINO-AMERICANO SOBRE RISCO GEOLÓGICO URBANO, 1,
Quadro 3 - Proposta de ordem de prioridade para a execução de intervenções estruturais para redução dos riscos identificados.

\begin{tabular}{c|l|c}
\hline $\begin{array}{c}\text { Ordem de } \\
\text { prioridade }\end{array}$ & \multicolumn{1}{|c|}{ Número e nome da área } & Setor \\
\hline 1 & 13. Jardim Paraíso I & 3 \\
\hline \multirow{2}{*}{2} & 3. Jardim Analândia & 4 \\
\cline { 2 - 3 } & 07. Jardim Idemori & 2 \\
\hline \multirow{2}{*}{3} & 17 a 20. Jardim Sampaio I, II, III e IV & Todos (*) \\
\hline \multirow{2}{*}{4} & 09. Jardim Jacira & 1 \\
\cline { 2 - 3 } & 13. Jardim Paraíso I & 1 \\
\cline { 2 - 3 } & 15. Jardim Pelúcio & 1 \\
\cline { 2 - 3 } & 16. Jardim Potuverá & 1 \\
\cline { 2 - 3 } & 22. Jardim São Marcos I & 1 \\
\hline \multirow{2}{*}{5} & 12. Jardim Marilu III & 2 \\
\cline { 2 - 3 } & 13. Jardim Paraíso I & 2 \\
\cline { 2 - 3 } & 25. Jardim São Pedro II & 1 \\
\cline { 2 - 3 } & 27. Jardim Tereza Maria / Centro & 1 \\
\cline { 2 - 3 } & 28. Mirante da Lagoa & 2 \\
\cline { 2 - 3 } & 33. Parque Paraíso / Guatemala & 1 \\
\hline \multirow{2}{*}{6} & 07. Jardim Idemori & 2 \\
\cline { 2 - 3 } & 14. Jardim Paraíso II & 1 \\
\hline
\end{tabular}

Anais... São Paulo: ABGE, 1990, p.457-468.

PREFEITURA MUNICIPAL DE ITAPECERICA DA SERRA. Plano municipal de redução de riscos. Itapecerica da Serra - SP, 2006.

ROSS, J.L.S., MOROZ, I. C. Mapa geomorfológico do Estado de São Paulo. Escala 1:500.000. 1997.

SANTOS, A.R. Dos. Geologia de Engenharia: conceitos, método e prática. São Paulo: ABGE (Publicação IPT 2797), 2002. 222p.

Artigo recebido em 28/06/2007 e aprovado em 17/12/2007.

\section{REM - Revista Escola de Minas 72 anos divulgando CIÊNCIA.} $\star \star * * * *$

www.rem.com.br 